\title{
Draining the posterior pericardial space: Pericardiotomy versus just another tube
}

\author{
Vincent R. Conti, MD
}

\footnotetext{
From the Division of Cardiothoracic Surgery, Department of Surgery, University of Texas Medical Branch, Galveston, Tex.

Disclosures: Author has nothing to disclose with regard to commercial support.

Received for publication Dec 19, 2016; accepted for publication Dec 27, 2016; available ahead of print Jan 27, 2017.

Address for reprints: Vincent R. Conti, MD, Division of Cardiothoracic Surgery, Department of Surgery, University of Texas Medical Branch, 301 University Blvd, Galveston, TX 77555-0528 (E-mail: vconti@utmb.edu).

J Thorac Cardiovasc Surg 2017;153:876-7

$0022-5223 / \$ 36.00$

Copyright (c) 2017 by The American Association for Thoracic Surgery

http://dx.doi.org/10.1016/j.jtcvs.2016.12.020
}

There are surely many surgical practices and techniques used in cardiac surgery that vary among surgeons and are assumed to be inconsequential with respect to outcomes. The review and meta-analysis of randomized trials by Gozdek and colleagues ${ }^{1}$ published in this issue of the Journal, which investigated whether adding drainage of the posterior pericardial space had a beneficial effect on several outcome variables, should stimulate the question of whether surgeons should reconsider their present practices. Their studies found 19 randomized, controlled trials that investigated this question, and they found after thorough review and statistical analysis that there was a significant beneficial effect from posterior pericardial drainage. Benefits included decreases in the incidences of cardiac tamponade, early and late pericardial effusion, and postoperative atrial fibrillation. Drainage of the posterior pericardial space was also associated with decreases in the incidence of postoperative death or cardiac arrest and in postoperative length of stay.

Considering all the studies, it should be pointed out that the largest study included 458 patients, whereas 6 of the studies included 100 or fewer patients. It should also be pointed out that all but 2 of these analyzed studies used the posterior pericardiotomy technique. Only 2 studies randomly allocated patients to undergo placement of a posterior pericardial chest tube versus no posterior pericardial drainage $^{2,3}$ and one of these was conducted in patients undergoing only ascending aortic surgery with or without valve surgery. ${ }^{2}$ Gozdek and colleagues ${ }^{1}$ addressed this question and did an added subgroup analysis stratified by operative technique and found no statistically significant differences between the technical approaches to posterior pericardial drainage with regard to the beneficial effects. They also point out in their discussion that the posterior tube option minimizes the risk of vein graft compression and bleeding from the additional pericardial incision, complications that were experienced in the trials that used the posterior pericardiotomy technique, as well as reducing the potential for cardiac herniation. studies. may fear.

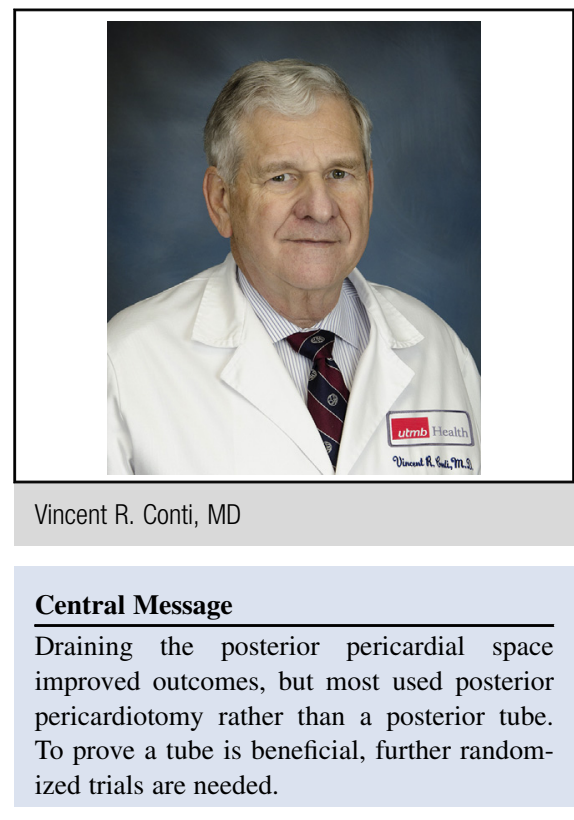

See Article page 865

In my survey of surgical colleagues, about half routinely place both an anterior tube and a posterior pericardial tube - usually a soft rubber flat or oval tube — and the others just place anterior or pleural tubes. None perform the posterior pericardiotomy procedure used in 17 of these 19

If indeed drainage of the posterior pericardial space with an extra chest tube can achieve the same beneficial effects documented in this study with posterior pericardiotomy, it should be advocated for all cardiac operations. It should be noted that the incidences of some adverse outcomes in the control groups in this study were higher than one would expect but should be accepted as true because of the randomization techniques used to ensure the comparability of the study groups.

There seems to be considerable reluctance among surgeons with whom this was discussed to perform the pericardiotomy procedure rather than adding a posterior pericardial tube. It would seem, given the data supporting the benefit of posterior pericardial drainage, that it will be necessary to perform further randomized trials to prove to surgeons that draining the posterior pericardium with an extra tube is indeed significantly beneficial and does not have any significant adverse effects that surgeons 


\section{References}

1. Gozdek M, Pawliszak W, Hagner W, Zalewski P, Kowalewski J, Paparella D, et al. Systematic review and meta-analysis of randomized controlled trials assessing safety and efficacy of posterior pericardial drainage in patients undergoing heart surgery. J Thorac Cardiovasc Surg. 2017; 153:865-75.
2. Eryilmaz S, Emiroglu O, Eyileten Z, Akar R, Yazicioglu L, Tasoz R, et al. Effect of posterior pericardial drainage on the incidence of pericardial effusion after ascending aortic surgery. J Thorac Cardiovasc Surg. 2006;132:27-31.

3. Kaya M, Iyigün T, Yazici P, Melek Y, Göde S, Güler S, et al. The effects of posterior pericardiotomy on pericardial effusion, tamponade, and atrial fibrillation after coronary artery surgery. Kardiochir Torakochirurgia Pol. 2014;11:113-8. 